\title{
The global male-bias in sex ratio at birth is sustained by the sex ratio genotypes of replacement offspring
}

\author{
Corry Gellatly ${ }^{1}[$
}

Received: 7 December 2018 / Accepted: 18 July 2019 / Published online: 7 August 2019

(c) The Author(s) 2019

\begin{abstract}
Throughout the world, there is a male-bias in the sex ratio at birth (SRB). It is not known whether this phenomenon has a genetic basis, though there is tentative evidence from genealogical and genomic studies that it may have. It has been proposed that the higher rate of male childhood mortality in humans is linked to the male-bias in SRB through parental investment, but this may only apply to facultative not genetic sex ratio adjustment. In previous population genetic models, elevated mortality in one sex (prior to breeding) has been shown not to affect the SRB, but these models did not consider the role of replacement births (i.e. births that only occur because a sibling died prematurely). In a set of population genetic modelling simulations, in which sex ratio is controlled by an autosomal gene expressed in the male line, this study shows that when there is replacement of dead offspring, this leads to a sustained bias in the SRB in the direction of the sex suffering the highest mortality. In the example of higher male mortality, this occurs, because replacement offspring are disproportionately drawn from fathers who were genetically predisposed to have initially had sons (because sons were more likely to die prematurely), and more likely to pass on male-biasing alleles to replacement offspring. To test the empirical basis for replacement births, an analysis of birth data from the Demographic and Health Survey program was conducted, which shows that parents do indeed tend to replace children who die prematurely.
\end{abstract}

Keywords Sex ratio gene $\cdot$ Infant mortality $\cdot$ Frequency dependent selection

\section{Introduction}

It is widely understood that the sex ratio at birth (SRB) is subject to a form of natural selection known as frequency dependent selection (Darwin 1871, 1874; Düsing 1884; Fisher 1930). If one sex becomes more frequent in the breeding population, this will cause the other sex, on average, to gain higher reproductive success, which leads to positive selection on any sex-biasing trait that causes more of the less frequent sex to be born, until that trait has increased over a number of generations and the sexes are produced in approximately equal frequency. In a general sense, we can

Electronic supplementary material The online version of this article (https://doi.org/10.1007/s10709-019-00074-2) contains supplementary material, which is available to authorized users.

Corry Gellatly

corry.gellatly@leicester.ac.uk

1 Department of Cardiovascular Sciences, University of Leicester, Glenfield General Hospital, Groby Road, Leicester LE3 9QP, UK say that sexually reproducing species produce equal numbers of males and females at birth, but there are many exceptions. In this study, I focus on why the human SRB is not equal, but instead male-biased. According to national-level statistics reported by the United Nations Population Division (2017) and based on 5 year averages, the SRB (as proportion of males) ranges from 0.504 to 0.535 (average: 0.513 ), whilst analysis of historical sources from several countries indicates the male-bias in SRB pre-dates the twentieth century (Gini 1908; Gilbert and Danker 1981; James 2000).

The concept of frequency dependent selection is well understood, but the process by which frequency dependent selection acts on the biological mechanism of sex-determination is less clear. Fisher's long established theory for how natural selection acts on the sex ratio states that genes which cause parents to expend their resources (including parental care) equally on each sex of offspring will spread toward fixation, because each sex contributes exactly half of the genetic material of future generations (Fisher 1930). This theory has been described as an example of an ESS, where selection results in the fixation of a single genotype that 
is immune to invasion by variant genotypes or mutations (Maynard Smith 1982). There are instances where the ESS may involve unequal production of males and females. For example, in cooperatively breeding species, greater production of the most helpful sex may lead to greater fitness benefits for parents or offspring [local resource enhancement] (Clark 1978), and where one sex competes for local breeding sites and the other sex disperses, selection may favour a skew in the sex ratio toward the dispersing sex [local resource competition] (Hamilton 1967; Clark 1978). However, these hypotheses are not obviously applicable to the bias in the human sex ratio, despite evidence that male dispersal in primate species is associated with a male-biased SRB (Johnson 1988; Silk and Brown 2008).

The prominent evolutionary explanation for the male bias in the human SRB is that a higher rate of male mortality in childhood serves to lower the resources (including parental care) expended by parents on males, which causes more males to be born in order to equalise the overall expenditure of parental resources on each sex (Fisher 1930). It is a hugely complex task to quantify the extent of parental care invested in offspring at the population level, hence empirical evaluation of the theory is not straightforward (Grant 2003), though studies have attempted to estimate relative parental investment in sample families (Page et al. 2019). It has been pointed out that control of the sex ratio would have to be facultative for the male-bias in SRB to have evolved in this way (Werren and Charnov 1978), although Fisher argued that selection results in the elimination of genes that cause parents to invest their resources unequally in the sexes, which is an argument for genetic rather than facultative control over the sex ratio. It is around the issue of genetic and facultative control of sex ratio that we need to be clear, because there is arguably a blurring of the lines in the literature.

In a system of facultative sex ratio control, we can expect the influence of health, social or environmental factors over the lifetime of an individual to affect the sex ratio among their offspring. A good example is maternal condition, which has been widely studied in relation to sex ratio, since Trivers and Willard (1973) predicted that in polygynous species, mothers in better condition will increase their reproductive success by facultatively adjusting the sex ratio among their offspring to produce more sons, because a well nurtured son can potentially out-reproduce a well nurtured daughter. The Trivers-Willard effect, as it has come to be known, has been tested in various species, with some of the strongest evidence for the effect in ungulate mammals (CluttonBrock et al. 1984; Sheldon and West 2004). In humans, the Trivers-Willard effect has been tested a number of times, and it has been proposed, for example, to explain a higher than expected number of sons born to billionaires (Cameron and Dalerum 2009) and more sons born to married, better educated and younger mothers in US linked birth statistics
(Almond and Edlund 2007). Nonetheless, evidence for the effect in humans is broadly inconclusive, with approximately half of published studies reporting null results (Lazarus 2002).

In a system of facultative sex ratio control, the link between the sex ratio adjustment response (which occurs to take advantage of prevailing conditions) and genetic return is not staggered over the generations in the same way as in a genetic system of sex ratio control. Individuals may make an adjustment to produce more sons when the operational sex ratio (OSR) is biased toward females, or more daughters when it is biased toward males, which results in greater reproductive success for offspring and more grandchildren being born. In humans, it has been proposed that this type of adaptive sex ratio control explains correlated trends in the SRB and OSR over time, in the historical Finnish population (Lummaa et al. 1998; Helle et al. 2008). In terms of a mechanism of facultative sex ratio adjustment in humans, there are several suggestions. James (1971, 1995), for example, argues that perceptions of the frequency of the opposite sex in the population affect how often people have intercourse, which affects the sex ratio by affecting the point at which conception occurs in relation to variations in hormone levels over the menstrual cycle. Grant (1990) similarly argues that variations in hormone levels around the time of conception affects the sex of offspring, with higher testosterone leading to a greater probability of a male birth. The consequence of this is that dominant females, or females in better condition, will have more sons, due to higher circulating testosterone. This can be described as a facultative system of sex ratio control, given that testosterone can vary in response to prevailing conditions. It may also be genetic system of sex ratio control, if as Grant (2003) suggests, female testosterone levels have a variable genetic component. The problem with this, however, is that there is no evidence for a maternal pattern of sex ratio inheritance in humans. In contrast, genealogical studies find evidence for a heritable component in the human sex ratio in the paternal line (Trichopoulos 1967; Curtsinger et al. 1983; Gellatly 2009), a pattern which is also observed in dairy cattle (Berry et al. 2011).

In a genetic system of sex ratio control, we may expect the sex ratio among an individual's offspring to be determined through the genes of the parent (to the extent that it is not determined by chance, or by a coexisting facultative system of sex ratio control), and therefore fixed at the birth of the parent. It has been shown with an individual-based population genetic model that frequency dependent selection can bring about an equilibrium sex ratio when there is genetic variability in an autosomal sex ratio determining gene that affects the sex ratio through the reproductive phenotype of one of the sexes (Gellatly 2009). In this model, a clear difference in the frequencies of sex ratio genotypes is observed between the sexes, in contradiction to a previous 
model which showed that autosomal genotypes cannot differ between the sexes unless they are subject to non-random disjunction (Shaw 1958). In support of the later model, a genome-wide association study (GWAS) involving 4183 males and 4659 females from Korea, found autosomal variation associated with sex, in coding regions linked to the reproductive system (Ryu et al. 2016). It seems that there is tentative evidence for an autosomal sex ratio determining gene, and clearly further genetic and demographic studies are required to investigate this. There is also a need for theoretical work to consider whether the male-bias in the human SRB arises through genetic selection, and whether the higher rate of male mortality in childhood could be a factor.

According to Fisher (1930), a higher rate of male mortality in childhood causes a male-bias in the SRB, because selection compensates for a situation in which parental investment per male is lower than per female, by raising the number males born to equalise the overall investment. In a classical equational model, it is possible demonstrate this by including the cost to parents of producing each sex as a variable, so that genetic return (in the grandchildren's generation) is a function of: (1) the cost of producing each sex, (2) the sex ratio among progeny, (3) the sex ratio in the population (e.g. Karlin and Lessard 1986; Kumm et al. 1994). In an individual-based population genetic model, on the other hand, parameters have to be implemented as genetic or life-history variables at the individual level, and to date, no such model has shown how parental investment in offspring can affect selection on an autosomal sex ratio gene. In an individual-based population genetic model, inheritance of autosomal alleles is randomised (in accordance with Mendel's law of segregation), so a difference in mortality of each sex (prior to breeding age) does not cause a bias in the SRB unless the mortality is correlated with sex ratio genotype (Gellatly 2009), but no epidemiological evidence has so far been produced that human premature mortality patterns are correlated with brood sex ratio. However, the effect of replacement births (i.e. births that only occur because a sibling died prematurely), has not previously been factored into individual-based population genetic models of sex ratio control. Yet, we can hypothesise that, across a population, replacement births will inherit different sex ratio genotypes to initial offspring, because they are drawn from families whose children have died, meaning that their existence in the population, and the genotypes of the parents that they are born to (and inherit their genotypes from), will be dependent on the distribution of childhood mortality by sex across the population. As such, the SRB may correlate with the distribution of childhood mortality by sex.

In this study, an individual-based population genetic modelling approach was used to test the effect of replacement births on the SRB, with autosomal genes determining the sex of children via the paternal phenotype. There were two codominant alleles (a male-biasing $m$ allele and a femalebiasing $f$ allele) and three genotypes ( $m m, m f$ and $f f$ ); males with the $\mathrm{mm}$ genotype had an $80 \%$ probability of fathering sons, males with the ff genotype a $20 \%$ probability, and males with the $m f$ genotype a 50\% probability. Although autosomal, the gene was not expressed in the maternal phenotype. Transmission of alleles from parents to offspring occurred by simulation of Mendelian rules of inheritance.

A series of 20 simulations were run, in which two parameters were varied: first, the percentage of premature deaths (deaths prior to breeding age) was varied for male and female offspring; second, the replacement rate for premature deaths was varied according to the sex of the offspring being replaced. If a premature death occurred, the genotype of the individual who died would not be included in the sums of genotypes available for breeding and parenting the next generation. The probability of a premature death being replaced by another offspring was determined by the replacement rate probability parameter for the sex of the offspring that died. The mortality rates for replacement offspring were the same for replacements as initial births. Each simulation was iterated for 500 generations.

To explore whether there is an empirical basis to the idea that parents will, to some extent, replace children who die, a study of available birth data from the Demographic and Health Survey (DHS) program was carried out. This included data from 290 surveys conducted in 81 developing countries and covering $>9$ million births. Analysis focussed on the number of births to women, dependent on the number of their children who had died prematurely and the sex of those children, to understand if women tended to have more children overall if they had lost one or more children.

It is well known that males suffer higher rates of mortality in infancy and childhood, due to congenital pathologies and inherent susceptibilities to disease (Kraemer 2000), but it is not clear whether parents are more likely to have a replacement child in the event of the death of a boy or a girl, though there are strong cultural preferences for sons in some countries, as evidenced by widespread sex-selective abortion of females and other family planning decisions related to son preference (Clark 2000; Chaudhuri 2012; Alkema et al. 2014; Gellatly and Petrie 2017). Analysis of the DHS data therefore also focused on whether the likelihood of child deaths being replaced was dependent on the sex of the children who had died.

\section{Materials and methods}

\section{Simulation modelling}

All code was written in the $\mathrm{R}$ language ( $\mathrm{R}$ Core Team 2017). Alleles were inherited according to Mendelian probabilities 


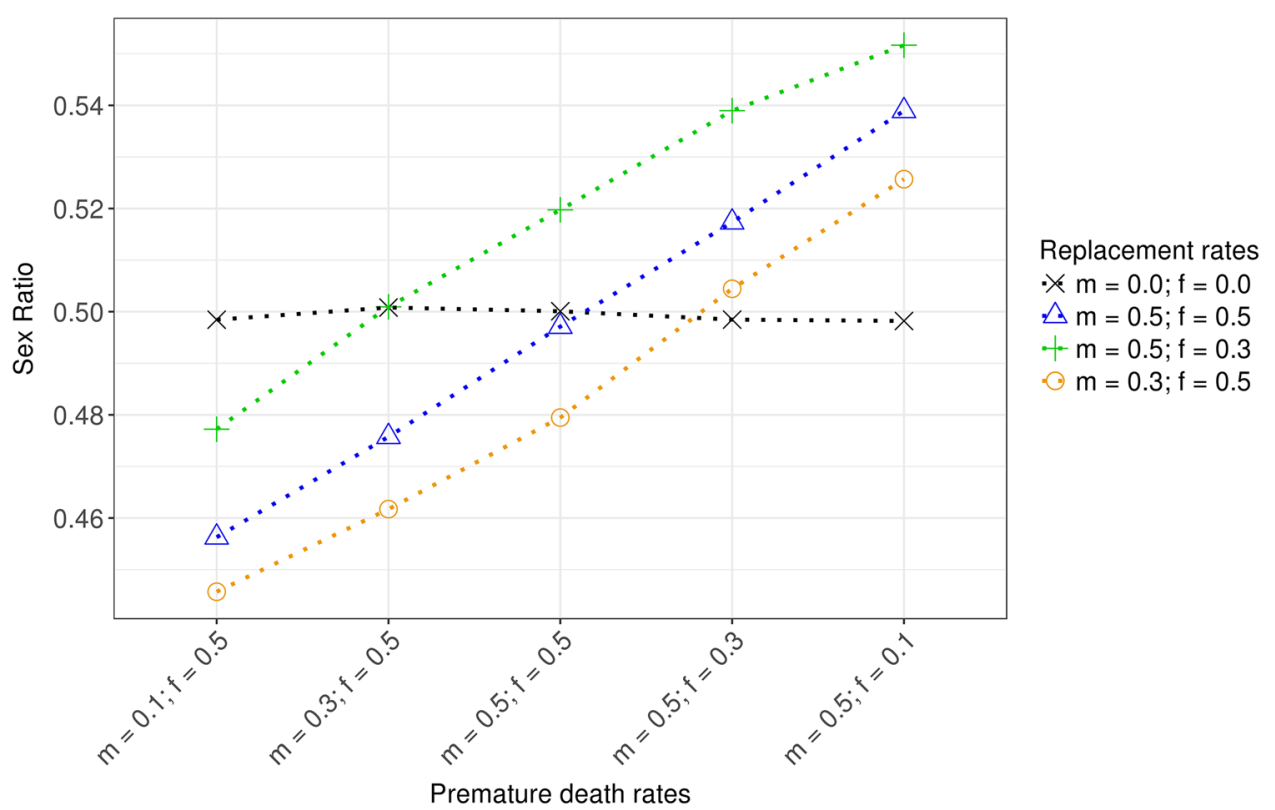

Fig. 1 Mean SRB over 500 generations, in simulations with sex ratio controlled by an autosomal gene expressed in the paternal line. In the first set of simulations [black crosses, Sim. A1-A5], there was no replacement of premature deaths for male (m) or female (f) offspring (replacement rate: $\mathrm{m}=0.0 ; \mathrm{f}=0.0$ ); in the second set [blue triangles, Sim. B1-B5] half of all male and female premature deaths were replaced (replacement rate: $\mathrm{m}=0.5 ; \mathrm{f}=0.5$ ); in the third set [green

generated by the R 'sample' function. The probability of dying before breeding (premature death rate) and the probability of a death being replaced (replacement rate), were generated with the 'rbinom' function. The 'sample' and 'rbinom' functions both make use of the Mersenne Twister pseudo-random number generator. All code is made available as Supplementary Information.

\section{Demographic analyses}

The 'birth recodes' datasets of 290 Demographic and Health Survey (DHS) surveys from 81 countries (Table S1) were used for the replacement births analysis. These data sets are based on interviews with women about their birth history, with each record relating to a different child and including information on the child's sex and age at death (if they had died at the time of the interview). Information on the paternity of the births is not available in the data.

The 290 survey data sets were combined and checked for the following errors: (1) duplicate birth errors-more than one record per birth, based on the 'BORD' (birth order) and 'CASEID' variables; (2) sibling errors-no sibling despite there being a 'B12' (succeeding birth interval) variable value, or a 'B12' value but no sibling; (3) family size errors - the count of children in the family did not match the 'V201' (total number of children ever born) variable value. pluses, Sim. C1-C5] replacement was higher for male premature deaths (replacement rate: $\mathrm{m}=0.5 ; \mathrm{f}=0.1$ ); in the fourth set [orange circles, Sim. D1-D5] replacement was higher for female premature deaths (replacement rate: $\mathrm{m}=0.1 ; \mathrm{f}=0.5$ ). There were five variations on the premature death rate for each set of simulations (x-axis), ranging from female-biased (premature death rate: $\mathrm{m}=0.1 ; \mathrm{f}=0.5$ ) to male-biased (premature death rate: $\mathrm{m}=0.5 ; \mathrm{f}=0.1$ )

When one of these errors was identified, then all births to that survey respondent (mother), were deleted, resulting in deletion of 309,052 birth records. After this, there were a total of $9,111,842$ birth records.

Analyses were based on a data selection that included only births to mothers who did not have twins, to avoid the difficulty of accounting for different levels of childhood mortality and replacement of child deaths in twins. The selection also only included births to women who were $>40$ at the time of the interview to select families that were highly likely to be complete $(<1 \%$ of children in the whole data set were born to mothers $>40$ ). This was necessary, because of the requirement to count children born later in a woman's reproductive life, who may have been replacements for children who had died. The analysed data set included a total 2,517,258 births.

\section{Results}

In the simulation models without replacement of premature deaths (Sim. A1-A5), the SRB remains approximately equal when there is a difference in premature mortality between the sexes (Fig. 1) (Table S2). This result is expected according to previous studies (in which replacement births were not factored into the models), which showed that a sex difference 
in mortality does not affect the primary sex ratio, because it does not alter the relative frequencies of the sex ratio determining genotypes in either of the sexes (Leigh 1970; Gellatly 2009).

In the simulations with an equal level of replacement of premature deaths (Sim. B1-B4), the average sex ratio over 500 generations was male-biased when the premature mortality rate was skewed toward males ( $\mathrm{Sim} . \mathrm{B} 4=0.517$, Sim. B5 = 0.539) (Table S2). The reason for this is that a greater proportion of the surviving replacement births were fathered by $\mathrm{mm}$ genotype males (and therefore inherited more $m$ alleles) than was the case with initial births, because a greater proportion of the initial offspring of $\mathrm{mm}$ genotype fathers were male, who died and were replaced. Likewise, the SRB became female-biased when the premature mortality rate was skewed toward females $(\mathrm{Sim} . \mathrm{B} 1=0.456$, Sim. B2 $=0.476$ ), because the surviving replacement births were more likely to have been fathered by ff genotype males (and therefore inherited more $f$ alleles), due to a greater proportion of the initial offspring of $f f$ genotype fathers being females who died and were replaced.

When the replacement rate was higher for either male (Sim. C1-C5) or female (Sim. D1-D5) premature deaths, the mean SRB became biased toward males or females respectively, because couples with a genetic tendency to produce the sex with the highest mortality rate were more likely to replace dead offspring.

In summary, the modelling shows that there are two nonexclusive scenarios in which we can expect a male-biased

Table 1 Mean number of children born per mother, according to the number of children who died $<10$ years of age

\begin{tabular}{ll}
\hline Children dead & Children born \\
\hline 0 & $4.78(\mathrm{n}=235,411, \mathrm{ci}= \pm 0.009)$ \\
1 & $6.26(\mathrm{n}=88,392, \mathrm{ci}= \pm 0.015)$ \\
2 & $7.40(\mathrm{n}=42,030, \mathrm{ci}= \pm 0.021)$ \\
3 & $8.32(\mathrm{n}=19,782, \mathrm{ci}= \pm 0.030)$ \\
4 & $9.04(\mathrm{n}=9510, \mathrm{ci}= \pm 0.041)$ \\
\hline
\end{tabular}

Confidence intervals are $95 \%$ sex ratio at birth: (1) higher male premature mortality combined with equal replacement of male and female premature deaths; (2) equal male and female premature death rates, but a higher rate of replacement of male premature deaths.

In the analysis of the combined DHS program data, the sex ratio of all births $=0.513(\mathrm{n}=2,517,258)$. The sex ratio of children who died $<1$ year of age $=0.552(n=190,038)$, $<5$ years of age $=0.5362(\mathrm{n}=288,346),<10$ years of age $=0.534(\mathrm{n}=323,374)$, and all child deaths $=0.535(\mathrm{n}$ $=534,689$ ). A higher rate of male premature mortality is one of conditions identified in the simulation modelling that causes the SRB to become skewed toward males, the other condition is replacement of children who die. To test for the occurrence of replacement of child deaths, the mean number of children born to mothers was calculated, aggregated by how many children under age 10 had died (Table 1).

The difference in total number of children born to mothers with no child deaths and those with 1 death is statistically highly significant (Welch two sample $t$ test: $\mathrm{t}=-167, \mathrm{df}=$ $150760, P<0.001$ ), and the difference increases with each additional child who dies.

There is no significant difference in the total number of children born when mothers lose either only male or only female children (up to 3 children in total) (Table 2), indicating that there is no sex difference in the replacement of male and female offspring in this data set.

In summary, the empirical analysis shows that there is a tendency for child deaths to be replaced, and that the parental decision to have another child is not affected by the sex of the children who die. The analysis also shows that the premature mortality rate is higher for male than female children.

\section{Discussion}

The results of this study support the proposition that the universal male-bias in the human SRB may have a genetic basis. In a set of individual-based population genetic modelling simulations, in which variant alleles of an autosomal gene affected the sex ratio through the male phenotype, it was found that the SRB of the population remained at
Table 2 Mean number of children born per mother, according to the number and sex of children who died $<10$ years of age

\begin{tabular}{|c|c|c|c|}
\hline \multicolumn{2}{|c|}{ Children dead } & \multirow[t]{2}{*}{ Children born } & \multirow[t]{2}{*}{ t-test } \\
\hline Male & Female & & \\
\hline 1 & 0 & $6.25(\mathrm{n}=47,488, \mathrm{ci}=0.021)$ & \\
\hline 0 & 1 & $6.25(\mathrm{n}=40,904, \mathrm{ci}=0.022)$ & $\mathrm{t}=0.358, \mathrm{df}=86,534, \mathrm{P}=0.720$ \\
\hline 2 & 0 & $7.50(\mathrm{n}=11,275, \mathrm{ci}=0.040)$ & \\
\hline 0 & 2 & $7.53(\mathrm{n}=8693, \mathrm{ci}=0.045)$ & $\mathrm{t}=0.978, \mathrm{df}=19,203, \mathrm{P}=0.328$ \\
\hline 3 & 0 & $8.49(\mathrm{n}=2846, \mathrm{ci}=0.075)$ & \\
\hline 0 & 3 & $8.52(\mathrm{n}=2098, \mathrm{ci}=0.086)$ & $\mathrm{t}=0.434, \mathrm{df}=4555.7, \mathrm{P}=0.664$ \\
\hline
\end{tabular}

Confidence intervals are $95 \%$. Welch two sample $t$-test 


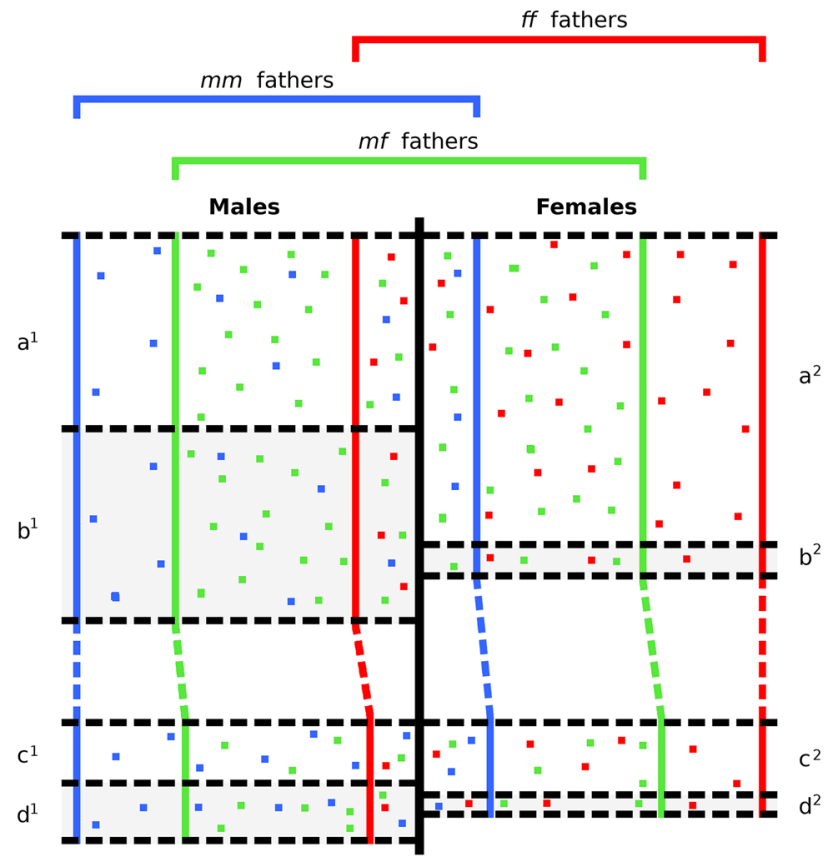

Fig. 2 Schematic diagram illustrating how the proportion of offspring fathered by $\mathrm{mm}$ genotype, as compared to $f f$ genotype males, is higher for replacement than initial offspring when the male premature mortality rate is $50 \%$ and female premature mortality rate is $10 \%$. Individual offspring (dots) are coloured according to the genotype of their fathers: blue ( $\mathrm{mm}$ genotype fathers-who have more sons); green ( $m f$ genotype fathers-who have equal sons and daughters); red ( $f f$ genotype fathers-who have more daughters). The vertical coloured lines indicate the relative proportions of offspring of each paternal genotype. The vertical black line separates male and female offspring, whilst the horizontal dashed black lines separate the initial offspring who survived childhood mortality $\left(\mathrm{a}^{1}\right.$ and $\left.\mathrm{a}^{2}\right)$ and initial offspring who died $\left(b^{1}\right.$ and $\left.b^{2}\right)$, as compared to the surviving replacement offspring $\left(\mathrm{c}^{1}\right.$ and $\left.\mathrm{c}^{2}\right)$ and replacement offspring who died $\left(\mathrm{d}^{1}\right.$ and $\left.\mathrm{d}^{2}\right)$. The same mortality rate affected the replacement offspring, hence why there are more surviving female replacement offspring despite more replacement offspring being fathered by $\mathrm{mm}$ genotype males

equality in a stable equilibrium (due to frequency dependent selection) when there were no replacement births (irrespective of any sex-difference in the premature mortality rate). The inclusion of replacement births for offspring who died prior to reproduction resulted in a sustained bias in the SRB, in the direction of the sex suffering a higher premature mortality rate. For example, when male premature mortality was higher than female premature mortality, the SRB became male-biased, because replacement offspring inherited a higher frequency of the male-biasing allele from their fathers, who because they were previously fathers of sons who had died, were more likely to carry (and pass on) the alleles for producing sons.

To illustrate how the sex ratio genotypes of replacement births can differ from those of initial births, a schematic diagram is provided (Fig. 2). First of all, this shows that despite a higher premature mortality rate for male offspring, there is no difference in the relative frequencies of genotypes between the fathers of all initial offspring $\left(\mathrm{a}^{1}\right.$ and $\left.\mathrm{a}^{2}\right)$ and the fathers of initial offspring who die $\left(b^{1}\right.$ and $\left.b^{2}\right)$, because mortality removes the offspring in the same relative frequencies at which they occur (with respect to paternal genotype). In contrast, the surviving replacements $\left(\mathrm{c}^{1}\right.$ and $\mathrm{c}^{2}$ ) are more likely than initial births to be fathered by an $\mathrm{mm}$ genotype male because they are mostly drawn from the families in which male offspring died. In subsequent generations, this raises the frequency of the $m$ allele in the population and causes an increase in the SRB, because the offspring of $\mathrm{mm}$ fathers inherit a higher frequency of the $m$ allele. Importantly, this applies to both male and female replacement offspring.

The empirical study of DHS birth data supports the findings of the population genetic modelling. It is well known that males suffer higher mortality in infancy and in childhood, and we see that infant and child mortality is higher for males than females in the DHS data. This data also shows that women whose children have died in childhood, on average, have more children. It is not clear from this analysis what the proximate explanation for this is. It may be that there is an instinctive or emotional need for parents to replace children who die, or that the death of a child frees up the time and resources needed to raise another. It is also possible that there are underlying economic factors, such that families having the most children are those suffering the greatest economic burden, and who as a consequence suffer the highest childhood mortality rate. There is a need for further research into the proximate cause of this finding, but it was not the focus of further research for this study because we can still ultimately conclude that children who die are replaced in significant number, whatever the underlying proximate reason for this.

The concept that the relative parental resources expended on each sex of offspring can affect the SRB (Fisher 1930) was not tested in this study, except to the extent that sex differences in childhood mortality might be considered as a proxy for parental investment. It was found that the sex ratio becomes biased toward the sex that suffers higher mortality when there is some replacement of childhood deaths, but this is not related to parental investment, it is related to genetic selection. It is not clear how parental investment could be included in an individual-based model in any way that it could affect the transmission of autosomal alleles, because genotype is fixed at birth (before parental care occurs), and inheritance is subject to Mendelian randomisation at the iteration of each generation. In a classical equational model, the cost of producing each sex may be added as a parameter to the model, so that genetic return becomes a function of this parameter, along with parental genotype, brood sex ratio and population sex ratio (e.g. Karlin and Lessard 1986; Kumm et al. 1994). However, it is not possible to enter cost/parental 
investment as a parameter into an individual-based model in this way, because parameters have to be implemented as genetic or life-history variables at the individual level.

There are various models that have demonstrated how the sex ratio may become biased away from equilibrium, e.g. through exceptional mortality (Werren and Charnov 1978), recruitment (Werren and Taylor 1984) or perturbation to the stable age distribution (West and Godfray 1997), but these models assume facultative control of the sex ratio by parents, which is a very different mode of sex ratio adjustment to the genetic one proposed here. Individuals in a genetic system of sex ratio control are passive, they do not adjust the sex of their offspring in response to the OSR in their generation, because their tendency to produce either more male or female offspring is fixed at birth.

A number of authors have argued that human sex ratio variation is largely under a system of facultative control, and is responsive to the operational sex ratio (OSR) (James 1971, 1995; Grant 1996; Lummaa et al. 1998; Helle et al. 2008). The logic of the genetic model put forward here, and in Gellatly (2009), is not so intuitive, because although the relative frequencies of differing sex ratio genotypes among males is what determines the SRB, the relative frequencies of these genotypes is unaffected by the OSR (in the same generation) and also unaffected by sex differentials in premature mortality (before we take replacement births into account). It is through differences in average mating success of males and females (which depends on whether they are among the rarer or more frequent sex) that male-biasing $(m)$ or female-biasing $(f)$ alleles are more likely to be passed on. This does not affect the sex ratio of the next generation, but the one after, when the offspring who inherit those alleles have their own children.

The evidence for a genetic component to the human sex ratio has several strands. First genealogical studies indicate that there is a paternal pattern of inheritance (Trichopoulos 1967; Curtsinger et al. 1983; Gellatly 2009). Second, there is evidence for an extra-binomial distribution in large familial datasets, which shows that some families have more males or females than expected by chance (Harris and Gunstad 1930a, b; Lindsey and Altham 1998). Third, there is considerable natural variation in SRB between populations. For example, the SRB of African countries is lower, on average, than for other parts of the world (Garenne 2002) and populations of African descent in the US and UK have lower sex ratios than the white population (Khoury et al. 1984; James 1984). Fourth, a genomewide association study (GWAS) in the Korean population, including 4183 males and 4659 females, identified autosomal variation associated with sex, in coding regions linked to the reproductive system (Ryu et al. 2016). However, further genomic research is required, as a well-powered GWAS meta-analysis across 51 studies, including 61,094 women and 53,769 men of European ancestry did not identify any common SNP differences between men and women (Boraska et al. 2012).

A potential route by which autosomal genetic variation may translate into variation in the SRB is via distortion to the ratio of $\mathrm{X}: \mathrm{Y}$ chromosome bearing sperm (X:Y sperm). There have been a number of studies in which the $\mathrm{X}: \mathrm{Y}$ sperm ratio in mammalian and human ejaculate has been counted, to determine if there is any variation associated with sex ratio. There have been mixed results from these studies, which may relate to the wide methodological differences between them. For example, Griffin et al. (1996), used dual-colour FISH to analyse semen samples from 24 men, in which an average of over 12,000 sperm were counted for each man. It was found that the ratio of $\mathrm{X}: \mathrm{Y}$ sperm was very close to parity, but there were five donors who exhibited a ratio of $\mathrm{X}: \mathrm{Y}$ sperm in their samples that was significantly different from $1: 1$ (the percentage $\mathrm{Y}$ sperm in these samples was 47.81 , $48.71,48.74,48.93$ and 51.32). In another study also using dual-colour FISH analysis, Graffelman et al. (1999) counted approximately 200 sperm for each of 176 Caucasian men, in which an average of $50.3 \%$ of sperm were Y-bearing, which is a significantly lower proportion than the $51.3 \%$ average for the ethnicity of the donors. Another approach has been to test individuals with an unusually high number of one sex of offspring. Dmowski et al. (1979) compared the sperm from 10 men who had 3 or more daughters, with sperm from 18 men who had fewer or no daughters, finding that 'normal' men had a percentage $Y$ sperm of $49 \pm 5$, whilst the men with 3 or more daughters had a percentage Y sperm of $43 \pm$ 6, a statistically significant difference. Bibbins et al. (1988) got similarly significant results from using sperm from 18 men who had fathered three or more daughters and no sons, compared with samples from 10 men who had fathered both sons and daughters. However, Irving et al. (1999) found no difference in $\mathrm{X}: \mathrm{Y}$ sperm for 12 men with 3 or more sons and 7 men with 3 or more daughters. There is a need for further research on $\mathrm{X}: \mathrm{Y}$ sperm in humans and how this relates to SRB, as many studies are either under-powered, reported from infertile couples (e.g. Johannisson et al. 2002; Eisenberg et al. 2012), or are designed to study the effect of toxin exposure on sperm (e.g. Tiido et al. 2005, 2006; Terrell et al. 2011), and therefore confounded with respect to the general male population. Interestingly, the evidence from cattle and other mammals is increasingly pointing to non-random variation in $\mathrm{X}: \mathrm{Y}$ sperm and an association with offspring sex ratio (Chandler et al. 2007; Gomendio et al. 2006; Malo et al. 2017; Edwards and Cameron 2014). This is a complex area requiring further research, as the morphology of sperm is highly variable and impacts on sex ratio and fertility, possibly via postmeiotic expression of sex-linked and autosomal genes during spermatogenesis (Wang et al. 2005). 
The other issue that needs consideration, in the context of a potential genetic system of sex ratio control, is what happens to the sex ratio between conception and birth. An excess of males, over and above that seen at birth, is observed among late stage abortions and stillbirths (when sexing is possible morphologically) (Crawford et al. 1987; McGregor et al. 1992; Astolfi and Zonta 1999). In a cytogenetic analysis of 342 spontaneous abortions, Evdokimova et al. (2000) showed a female bias among the earliest abortuses. Boklage (2005) then reasoned that because the majority of abortions occur during embryogenesis (within 8 weeks of conception) and evidence for an excess of Y-bearing sperm in human semen was lacking, there must be an excess of female abortions during embryogenesis. A pattern of excess female mortality up to week 10 to 15 , then excess male mortality was confirmed by Orzack et al. (2015) who used multiple methods, including chorionic villus sampling, amniocentesis, and analysis of embryonic and foetal stage pregnancies to estimate the sex ratio at conception, finding it to be approximately equal.

The finding that the sex ratio at conception is equal may be interpreted as evidence of a non-adaptive explanation for the male-bias in the human sex ratio, in which the sex ratio at conception is the outcome of random disjunction of $\mathrm{X}$ and $\mathrm{Y}$ chromosomes into sperm during meiosis, and a malebiased SRB then derives from the sex differences in prenatal mortality. The counter argument to this is that selection will compensate for higher prenatal mortality of either sex, so that the SRB, rather than the sex ratio at conception, will reflect the selective pressure. This counter argument may not hold in a system in which the cost (in terms of parental investment) required to raise each sex is a determinant of the sex ratio at the end of the period of investment, as predicted by Fisher (1930), because the relative mortality of each sex in utero would impact on investment and affect the sex ratio. However, the genetic model presented here functions irrespective of the degree of parental care invested in each sex, and it is the sex ratio of individuals being recruited into the model, i.e. the sex ratio at birth, that is subject to selection.

The role of replacement births is interesting-these individuals inherit different sex ratio genotypes than initial births, because the pool of fathers that they are drawn from are more likely to have the genotype for fathering males (when male childhood mortality is higher than female), because they were more likely to initially have a son and therefore have a child who died and was replaced. It might be expected that the skew in SRB caused by a sex difference in childhood mortality and replacement births would be corrected for in the long-term by frequency dependent selection, but the simulation modelling shows that this is not the case, and that a long-term bias in SRB is sustained. In theory, the magnitude of the bias in the SRB will depend on the magnitude of difference in childhood mortality between the sexes, and the extent to which offspring who die are replaced. It ought to be possible to test this empirically, given sufficiently robust population data.

Acknowledgements I am grateful to Marion Petrie for comments on an early draft of the manuscript.

Data availability The simulation modelling code is made freely available as supplementary information. Demographic and Health Survey (DHS) data is available at https://dhsprogram.com upon registration, at no cost for legitimate academic research.

\section{Compliance with ethical standards}

Conflict of interest The author declares that he has no conflict of interest.

Open Access This article is distributed under the terms of the Creative Commons Attribution 4.0 International License (http://creativeco mmons.org/licenses/by/4.0/), which permits unrestricted use, distribution, and reproduction in any medium, provided you give appropriate credit to the original author(s) and the source, provide a link to the Creative Commons license, and indicate if changes were made.

\section{References}

Alkema L, Chao FQ, You DZ, Pedersen J, Sawyer CC (2014) National, regional, and global sex ratios of infant, child, and under-5 mortality and identification of countries with outlying ratios: a systematic assessment. Lancet Glob Health 2(9):e521-e530. https://doi. org/10.1371/journal.pone.0101112

Almond D, Edlund L (2007) Trivers-Willard at birth and one year: evidence from US natality data 1983-2001. Proc R Soc Biol Sci Ser B 274(1624):2491-2496. https://doi.org/10.1098/rspb.2007.0524

Astolfi P, Zonta LA (1999) Risks of preterm delivery and association with maternal age, birth order, and fetal gender. Hum Reprod 14(11):2891-2894

Berry DP, Kearney JF, Roche JR (2011) Evidence of genetic and maternal effects on secondary sex ratio in cattle. Theriogenology 75(6): 1039-1044

Bibbins PE, Lipshultz LI, Ward JB, Legator MS (1988) Fluorescent body distribution in spermatozoa in the male with exclusively female offspring. Fertil Steril 49(4):670-675

Boklage CE (2005) The epigenetic environment: secondary sex ratio depends on differential survival in embryogenesis. Hum Reprod 20(3):583-587

Boraska V, Jeroncic A, Colonna V, Southam L, Nyholt DR et al (2012) Genome-wide meta-analysis of common variant differences between men and women. Hum Mol Genet 21(21):4805-4815

Cameron EZ, Dalerum F (2009) A Trivers-Willard effect in contemporary humans: male-biased sex ratios among billionaires. PLoS ONE 4(1):e4195. https://doi.org/10.1371/journal.pone.0004195

Chandler JE, Taylor TM, Canal AL, Cooper RK, Moser EB, McCormick ME et al (2007) Calving sex ratio as related to the predicted Y-chromosome-bearing spermatozoa ratio in bull ejaculates. Theriogenology 67(3):563-571

Chaudhuri S (2012) The desire for sons and excess fertility: a household-level analysis of parity progression in India. Int Perspect Sex Reprod Health 38(4):178-186. https://doi.org/10.1363/3817812

Clark AB (1978) Sex-ratio and local resource competition in a prosimian primate. Science 201(4351):163-165 
Clark S (2000) Son preference and sex composition of children: evidence from India. Demography 37:95-108. https://doi. org/10.2307/2648099

Clutton-Brock TH, Albon SD, Guinness FE (1984) Maternal dominance, breeding success and birth sex-ratios in red deer. Nature 308(5957):358-360. https://doi.org/10.1038/308358a0

Crawford MA, Doyle W, Meadows N (1987) Gender differences at birth and differences in fetal growth. Hum Reprod 2(6):517-520

Curtsinger JW, Ito R, Hiraizumi Y (1983) A 2-generation study of human sex-ratio variation. Am J Hum Genet 35(5):951-961

Darwin C (1871) The descent of man, 1st edn. Murray, London

Darwin C (1874) The descent of man, 2nd edn. Murray, London

Dmowski WP, Gaynor L, Rao R, Lawrence M, Scommegna A (1979) Use of albumin gradients for $\mathrm{X}$-sperm and $\mathrm{Y}$-sperm separation and clinical experience with male sex preselection. Fertil Steril 31(1):52-57

Düsing C (1884) Die Regulierung des Geschlechtsverhältnisses bei der Vermehrung der Menschen, Tiere und Pflanzen. Jenaische Zeitschrift für Naturwiss 17:593-940

Edwards AM, Cameron EZ (2014) Forgotten fathers: paternal influences on mammalian sex allocation. TREE 29(3):158-164. https ://doi.org/10.1016/j.tree.2013.12.003

Eisenberg ML, Murthy L, Hwang K, Lamb DJ, Lipshultz LI (2012) Sperm counts and sperm sex ratio in male infertility patients. Asian J Androl 14(5):683-686

Evdokimova VN, Nikitina TV, Lebedev IN, Sukhanova NN, Nazarenko SA (2000) About the sex ratio in connection with early embryonic mortality in man. Ontogenez 31(4):251-257

Fisher RA (1930) The genetical theory of natural selection. Oxford University Press, Oxford

Garenne M (2002) Sex ratios at birth in African populations: a review of survey data. Hum Biol 74:889-900

Gellatly C (2009) Trends in population sex ratios may be explained by changes in the frequencies of polymorphic alleles of a sex ratio gene. Evol Biol 36:190-200

Gellatly C, Petrie M (2017) Prenatal sex selection and female infant mortality are more common in India after firstborn and secondborn daughters. J Epidemiol Community Health 71:269-274

Gilbert K, Danker H (1981) Changes of sex ratio in Germany 18261978. Acta Anthropogenet 5:89-110

Gini C (1908) Il Sesso dal Punto di Vista Statistico. Sandron, Milan

Gomendio M, Malo AF, Soler AJ, Fernandez-Santos MR, Esteso MC, Garcia AJ et al (2006) Male fertility and sex ratio at birth in red deer. Science 314(5804):1445-1447

Graffelman J, Fugger EF, Keyvanfar K, Schulman JD (1999) Human live birth and sperm-sex ratios compared. Hum Reprod 14(11):2917-2919

Grant VJ (1990) Maternal personality and sex of infant. Br J Med Psychol 63(3):261-266

Grant VJ (1996) Sex determination and the maternal dominance hypothesis. Hum Reprod 11:2371-2375

Grant VJ (2003) The maternal dominance hypothesis: questioning Trivers and Willard. Evol Psychol 1:96-107

Griffin DK, Abruzzo MA, Millie EA, Feingold E, Hassold TJ (1996) Sex ratio in normal and disomic sperm: evidence that the extra chromosome 21 preferentially segregates with the $\mathrm{Y}$ chromosome. Am J Hum Genet 59(5):1108-1113

Hamilton WD (1967) Extraordinary sex ratios. Science 156(3774):477-488

Harris JA, Gunstad B (1930a) The correlation between the sex of human siblings. I. The correlation in the general population. Genetics 15(5):445-461

Harris JA, Gunstad B (1930b) The problem of the relationship between the number and the sex of human offspring. Am Nat 64(695):495-508
Helle S, Kaar P, Helama S, Jokela J (2008) Do humans adjust offspring sex according to the local operational sex ratio? Evol Ecol Res 10(5):775-785

Irving J, Bittles A, Peverall J, Murch A, Matson P (1999) The ratio of $\mathrm{X}$ - and Y-bearing sperm in ejaculates of men with three or more children of the same sex. J Assist Reprod Genet 16(9):492-494

James WH (1971) Cycle day of insemination, coital rate, and sex ratio. Lancet 297:112-114

James WH (1984) The sex-ratios of black births. Ann Hum Biol 11(1):39-44

James WH (1995) What stabilizes the sex-ratio. Ann Hum Genet $59: 243-249$

James WH (2000) Secular movements in sex ratios of adults and of births in populations during the past half-century. Hum Reprod 15:1178-1183

Johannisson R, Leuschner E, Hüppe M, Hinrichs F, Al-Hasani S, Diedrich K, Schwinger E, Mennicke K (2002) Increased frequency of X-bearing sperm in males from an infertility clinic: analysis by two-color fluorescence in situ hybridization. Cytogenet Genome Res 98(4):240-244. https://doi.org/10.1159/000071041

Johnson CN (1988) Dispersal and the sex-ratio at birth in primates. Nature 332(6166):726-728

Karlin S, Lessard S (1986) Theoretical studies on sex ratio evolution (monographs in population biology-22). Princeton University Press, Princeton

Khoury MJ, Erickson JD, James LM (1984) Paternal effects on the human sex-ratio at birth-evidence from interracial crosses. Am J Hum Genet 36(5):1103-1111

Kraemer S (2000) The fragile male. BMJ 321(7276):1609-1612

Kumm J, Laland KN, Feldman MW (1994) Gene-culture coevolution and sex-ratios - the effects of infanticide, sex-selective abortion, sex selection, and sex-biased parental investment on the evolution of sex-ratios. Theor Popul Biol 46(3):249-278. https://doi. org/10.1006/tpbi.1994.1027

Lazarus J (2002) Human sex ratios: adaptations and mechanisms, problems and prospects. In: Hardy ICW (ed) Sex ratios: concepts and research methods. Cambridge University Press, Cambridge, pp 287-311

Leigh EG (1970) Sex ratio and differential mortality between sexes. Am Nat 104(936):205-210. https://doi.org/10.1086/282650

Lindsey JK, Altham PME (1998) Analysis of the human sex ratio by using overdispersion models. J R Stat Soc Ser C-Appl Stat 47:149-157

Lummaa V, Merila J, Kause A (1998) Adaptive sex ratio variation in pre-industrial human (Homo sapiens) populations? Proc R Soc Biol Sci Ser B 265:563-568

Malo AF, Martinez-Pastor F, Garcia-Gonzalez F, Grade J, Ballou JD, Lacy RC (2017) A father effect explains sex-ratio bias. Proc R Soc Biol Sci Ser B 284(1861):20171159

Maynard Smith J (1982) Evolution and the theory of games. Cambridge University Press, Cambridge

McGregor JA, Leff M, Orleans M, Baron A (1992) Fetal gender differences in preterm birth: findings in a North American cohort. Am J Perinatol 9(1):43-48

Orzack SH, Stubblefield JW, Akmaev VR, Colls P, Munne S, Scholl $\mathrm{T}$ et al (2015) The human sex ratio from conception to birth. PNAS 112(16):E2102-E2111

Page AE, Myers S, Dyble M, Migliano A (2019) Why so many Agta boys? Explaining 'extreme' sex ratios in Philippine foragers. Evol Hum Sci 1:e1. https://doi.org/10.1017/ehs.2019.4

R Core Team (2017) R: a language and environment for statistical computing. R Foundation for Statistical Computing, Vienna

Ryu D, Ryu J, Lee C (2016) Genome-wide association study reveals sex-specific selection signals against autosomal nucleotide variants. J Hum Genet 61:423-426. https://doi.org/10.1038/ jhg.2015.169 
Shaw RF (1958) The theoretical genetics of the sex ratio. Genetics 43:149-163

Sheldon BC, West SA (2004) Maternal dominance, maternal condition, and offspring sex ratio in ungulate mammals. Am Nat 163(1):40-54

Silk JB, Brown GR (2008) Local resource competition and local resource enhancement shape primate birth sex ratios. Proc $\mathrm{R}$ Soc Biol Sci Ser B 275(1644):1761-1765

Terrell ML, Hartnett KP, Marcus M (2011) Can environmental or occupational hazards alter the sex ratio at birth? A systematic review. Emerging Health Threats J 4:7109. https://doi. org/10.3402/ehtj.v4i0.7109

Tiido T, Rignell-Hydbom A, Jonsson B, Giwercman YL, Pedersen HS, Wojtyniak B et al (2006) Impact of PCB and p, p'-DDE contaminants on human sperm Y: X chromosome ratio: Studies in three European populations and the Inuit population in Greenland. Environ Health Perspect 114(5):718-724

Tiido T, Rignell-Hydbom A, Jonsson B, Giwercman YL, Rylander L, Hagmar L, Giwercman A (2005) Exposure to persistent organochlorine pollutants associates with human sperm Y:X chromosome ratio. Hum Reprod 20(7):1903-1909
Trichopoulos D (1967) Evidence of genetic variation in the human sex ratio. Hum Biol 39:170-175

Trivers RL, Willard DE (1973) Natural-selection of parental ability to vary sex-ratio of offspring. Science 179:90-92

United Nations Population Division (2017) World population prospects: 2017 revision. WDI database archives, dataset ID: 57, indicator ID: SP.POP.BRTH.MF

Wang PJ, Page DC, McCarrey JR (2005) Differential expression of sex-linked and autosomal germ-cell-specific genes during spermatogenesis in the mouse. Hum Mol Genet 14(19):2911-2918

Werren JH, Charnov EL (1978) Facultative sex-ratios and populationdynamics. Nature 272:349-350

Werren JH, Taylor PD (1984) The effects of population recruitment on sex ratio selection. Am Nat 124:143-148

West SA, Godfray HCJ (1997) Sex ratio strategies after perturbation of the stable age distribution. J Theor Biol 186(2):213-221

Publisher's Note Springer Nature remains neutral with regard to jurisdictional claims in published maps and institutional affiliations. 